\title{
The Power of Prejudice: Cross-cultural Competency and Muslim Populations
}

\author{
Rania Awaad, M.D., Aneeqa Abid, and Soraya Fereydooni*
}

\section{Introduction}

Oh people! We created you from a male and a female and made you into nations and tribes so that you may know one another. Verily the noblest of you in the sight of Allah is the Most God-fearing of you. Surely, Allah is All-Knowing, All-Aware. (49:13)

This oft-cited Quranic verse encapsulates the Islamic worldview on the raison d'être of different groups of people and ethnicities, thereby highlighting the importance of cross-cultural communication and Islam's role in transcending these differences. The same worldview can be adopted in psychiatric practice to provide culturally competent patient-centered care. This paper introduces a clinical vignette of a Muslim patient with poor mental health and her experiences living in the US as a religious minority. The vignette frames the following discussion in the context of rising hate in the country and brings to light the consequences of Islamophobia on the mental health of American Muslim populations. The psychology of outgroup hate is explained by analyzing the literature produced on the interrelated topics of stereotypes, discrimination, prejudice, and xenophobia, and concludes with tools available for cross-cultural competency in a clinical setting.

Keywords: Islamophobia, psychology, mental health, discrimination, racism, stereotypes, prejudice

\section{Case Study}

Renda (pseudonym) is a 45-year-old Palestinian-American married woman with four children. Renda was born and raised in the US, as were all of her children. She has been experiencing symptoms of irritability, difficulty in sleeping, and de-

\footnotetext{
* Rania Awaad, M.D., is a practicing Psychiatrist based at the Stanford University School of Medicine; a Clinical Associate Professor in the Stanford Department of Psychiatry and Behavioral Sciences; and a researcher and the Director of the Stanford Muslims and Mental Health Lab. Aneeqa Abid is a Public Policy Major at Stanford University with a demonstrated history of working and interning in the nonprofit sector and research (including wet lab). Soraya Fereydooni is a Health Specialist at the VA Palo Alto Health Care System Center for Innovation to Implementation (Ci2i).
} 
pression. She reports that much of her stress is related to her children. Her 10year-old son has been misbehaving in school and displays what she described as "mood swings" and "temper tantrums." As an involved, religiously observant Muslim parent who wears hijab, she wants to "represent Islam in a good light" to fellow parents at her son's school. She worries about her children being discriminated against by teachers and other students due to their religion, ethnicity, and perceived immigrant status. Her 14-year-old son has experienced an instance of bullying at school during which he was called a "terrorist" by another student.

\section{Islamophobia and Mental Health}

Today, hate in the United States is undeniably on the rise. The current president won an election after making many hateful and belittling comments about women, Muslims, those with disabilities, and people of color. During that election cycle, nine African Americans were shot down in a church after welcoming the shooter to a Bible study in Charleston, South Carolina. Anti-Semitic messages and symbols were sprayed onto the wall of an elementary school in Colorado. In New Zealand, 51 worshippers were murdered while attending the Friday congregational prayer - the two terrorists claimed to be inspired by President Trump, whom they praised and dubbed "a symbol of renewed white identity." These are just a few examples of the many xenophobic hate crimes that have occurred globally. In light of these recent acts, people have protested in large numbers nationwide. This section will focus on Islamophobia's effect on the mental health of American Muslim populations and the need for an appropriate response within the clinical setting.

With the recent rise of Islamophobia and anti-Muslim sentiments, American Muslim communities have experienced ongoing stressors that have detrimental effects on their mental health. ${ }^{1}$ A survey of 1,050 Muslims in the United States found that $42 \%$ of participants under the age of 30 reported that within the past year they had been verbally taunted, treated with suspicion, physically threatened or attacked, or targeted by police because they were Muslim. ${ }^{2}$ While many of these stressors are caused by overt forms of discrimination, research shows that Muslims endured subtler or ambiguous forms of discrimination at higher levels, such as being stared at or ignored.

\footnotetext{
${ }^{1}$ Sara Ali and Rania Awaad, "Islamophobia and Public Mental Health: Lessons Learned from Community Engagement Projects," Islamophobia and Psychiatry (2018): 375-90. https://doi.org/ 10.1007/978-3-030-00512-2_31.

2 Tom Rosentiel, "Muslim Americans: Middle Class and Mostly Mainstream," Pew Research Center (December 30, 2019). https://www.pewresearch.org/2007/05/22/muslim-americans-middleclass-and-mostly-mainstream/.
} 
These discrimination-based stressors will undoubtedly have severe consequences on the mental health of many of the affected individuals. This challenge is further aggravated by multiple barriers to seeking help, including mental health stigma, lack of culturally and religiously sensitive mental health services, and fear of discrimination by mental health providers. ${ }^{3}$ Findings also showed that discrimination against Muslims was associated with poor healthcare-seeking behavior. Women who reported wearing religious attire also reported more discrimination in health care settings, and one study found that religious clothing influences the care that Muslim patients receive. ${ }^{4}$

The current Islamophobic environment, especially in Western countries, further increases anxiety. One study, which examined data collected from 72 American Muslims between 2003-2006, sought to investigate the impact of stigma on Muslim responses to 9/11. The study found that heightened perceptions of stigma against Muslims and Arabs predicted negative emotional, cognitive, and behavioral responses such as individuals feelings threatened, believing that they must prove to others they are American, and changing their daily routine out of fear of violence or discrimination. ${ }^{5}$ Furthermore, in a study on discrimination, identity, and anxiety symptoms, $87 \%$ of the American Muslims sampled reported experiencing some kind of religious-based discrimination within the past year. Such discrimination predicted higher levels of depressive and anxiety symptoms. ${ }^{6}$ These findings demonstrate that Muslims are aware of the Islamophobic nature of their environment and that many live in anticipation of being subjected to poor treatment or discrimination.

Coping with stigma is important for managing the stress and anxiety that comes with experiencing stigma. One study explored stigma management strategies by collecting ethnographic data from Muslim youth and adults at a mosque in a major American city. The study found that although Muslims are not constantly suffering from stigma's negative effects, they are often in situations of potential or anticipated stigma and thus must learn potential responses to it. This study highlights important aspects of Muslim experiences and responses to belonging to a stigmatized group. For example, it found that significant time and effort are spent in managing stigma, including hypothetical, anticipated, and present situations. Additionally, it also found that leaders often encourage young Muslims to

\footnotetext{
${ }^{3}$ Ali and Awaad, "Islamophobia and Public Mental Health."

${ }^{4}$ Goleen Samari, Héctor E. Alcalá, and Mienah Zulfacar Sharif, "Islamophobia, Health, and Public Health: A Systematic Literature Review," American Journal of Public Health 108, no. 6 (2018). https://doi.org/10.2105/ajph.2018.304402.

${ }^{5}$ Saera R. Khan, "Post 9/11: The Impact of Stigma for Muslim Americans," Peace and Conflict: Journal of Peace Psychology 20, no. 4 (2014): 580-82. https://doi.org/10.1037/pac0000063.

${ }^{6}$ H. Steven Moffic, John R. Peteet, Ahmed Zakaria Hankir, and Rania Awaad. Islamophobia and Psychiatry: Recognition, Prevention, and Treatment. Cham, Switzerland: Springer, 2019.
} 
remain passive when responding to stigmatizing situations, often based on religious and cultural teachings, to promote peace and harmony. ${ }^{7}$

Islamophobia is a serious and rising issue that has widespread effects on interpersonal relationships and on the community level. One study found that fear of stigma and stereotyping results in social marginalization that deprives Muslims of social engagement's health-promoting effects. Anticipating harassment in the public arena negatively affects how they engage with other people, thereby making the development of community life rather challenging. Additionally, Islamophobic incidents perpetuate a sense of insecurity within the larger Muslim community and could result in trauma by proxy. This was clear after the 2019 Christchurch mass shooting, which resulted in widespread fear, anger, and anxiety in Muslim communities worldwide.

The Southern Poverty Law Center, an American legal and civil rights advocacy organization, published a list of several steps for an individual to take in response to hate crimes. These steps include being proactive in addressing biases, teaching acceptance, and supporting victims in times of vulnerability. Clinicians are often at the forefront of supporting victims of hate when they are most vulnerable. Thus, it is crucial, now more than ever, to increase cultural competency in clinical settings so that when patients or clients come in with a history of identitybased discrimination, clinicians can be culturally sensitive and literate about the issues their patients face.

\section{Racism, Xenophobia, and Islamophobia}

In his last sermon, Prophet Muhammad (peace be upon him) addressed his followers, who had come from various tribal societies. He spoke out against the racism and bias that had plagued pre-Islamic society and still existed at the end of his prophethood:

O People! Indeed your Lord is but one Lord, and indeed your father is but one (Adam). An Arab is no better than a non-Arab, and non-Arab is no better than an Arab; and no dark-skinned person is better than a light-skinned person, nor is a light-skinned person better than a dark-skinned person, except in piety. The most favored in the sight of Allah among you are the most righteous.

The issue of racism was a significant problem in sixth-century Arabia and remains a significant issue today. Tragedies such as the 2015 Chapel Hill and the 2019 Christchurch shootings have shaken Muslim communities worldwide. These incidents have forced Muslim minorities living in Western countries to face the realities of racism, xenophobia, and Islamophobia. This section will take a closer

\footnotetext{
7 John O’Brien, "Spoiled Group Identities and Backstage Work," Social Psychology Quarterly 74,
} no. 3 (April 2011): 291-309. https://doi.org/10.1177/0190272511415389. 
look at the concepts and phenomena associated with Islamophobia: implicit bias, stereotyping, prejudice, racism, and xenophobia. These concepts, although distinct, all play a role in Islamophobia. Here, the associations among concepts, along with definitions and examples, will be discussed.

Stereotypes are the beliefs people hold about different groups of people, which may or may not be accurate. ${ }^{8}$ Understanding the stereotypes and perceptions of groups is extremely important for comprehending the social world. Many social psychologists, including the prominent 20th-century psychologist Solomon Asch, have argued that understanding how the individual and group influence one another is key to understanding social behavior. ${ }^{9}$ Furthermore, stereotypes are dangerous because of the tendency people have to continue believing in them despite evidence suggesting their falsehood, thereby making them even more important to address.

Stereotypes facilitate an understanding of the social world, helping people understand and form explanations about others. Stereotyping occurs by mentally categorizing others and detecting similarities and differences among people. When meeting a stranger, stereotypes serve as a type of heuristic used to form quick impressions and save both time and energy. While convenient, using the known stereotypes of a group to judge an individual ignores the diversity and complexity of that individual. Known stereotypes are shared beliefs that stem from a common "cultural pool of knowledge" and thus produce similar views. Just as members of a group conform to typical group behavior, they also conform to those group ideas and views that make stereotypes a normative belief. ${ }^{10}$

While stereotypes are merely ideas, prejudice is the actual feeling and attitude directed toward different groups of people. Prejudice is rooted in stereotypes and defined as "an antipathy based upon a faulty and inflexible generalization." 11 Strictly speaking, it may be either positive or negative. However, in common usage it refers to feelings of animosity toward the members of a particular racial, ethnic, religious, gender, or age group. One must also be cognizant of the fact that prejudice is an attitude and not a behavior. It is a "prejudgment" based on assumptions rather than on actual experiences.

Several theories discuss the possible reasons for prejudice. This section will discuss two: the process of socialization and the principle of relative deprivation.

${ }^{8}$ Charles M. Judd and Bernadette Park, "Definition and Assessment of Accuracy in Social Stereotypes," Psychological Review 100, no. 1 (1993): 109-28. https://doi.org/10.1037/0033-295x.100. 1.109.

${ }^{9}$ Craig McGarty, Russell Spears, and Vincent Y. Yzerbyt, Stereotypes as Explanations: The Formation of Meaningful Beliefs about Social Groups (Cambridge: Cambridge Univ. Press, 2002).

${ }^{10}$ Ibid.

${ }^{11}$ Chris G. Sibley and Danny Osborne, "Prejudice." The SAGE Encyclopedia of Political Behavior (2017). https://doi.org/10.4135/9781483391144.n292. 
The process of socialization describes prejudice as a learned behavior, for its proponents contend that adults, who are responsible for socializing their children, also pass on their prejudices. ${ }^{12}$ Children, in turn, comply with these social norms as a part of social conformity. Prejudices that become social norms increase their foothold in society. The second theory, the principle of relative deprivation, emphasizes prejudice's role in scapegoating. This idea demonstrates that individuals have a tendency to blame others when they find themselves in poor conditions. Typically, the groups that are blamed or used as scapegoats are minorities and women. ${ }^{13}$ This behavior is explained by the "ultimate attribution error," which describes the tendency of individuals to perceive the same actions carried out by in-group members more positively than the actions carried out by out-group members. ${ }^{14}$ The "realistic conflict theory" further notes that this behavior is exacerbated by deprivation, competition, and economic distress. ${ }^{15}$

Prejudice may often lead to discrimination, a behavior rather than simply an attitude. Discrimination, which entails different treatment of individuals based on group identity (including race, age, gender, religion, or disability), commonly happens in the form of physical harm and the forceful exclusion of certain groups from society. A clear historical example in the United States is the horrific treatment of Native Americans, who were forced out of their homes and nearly driven to extinction. Discrimination can be a significant source of stress for individuals, a reality that negatively impacts their health. Several studies demonstrate a link between perceived discrimination and clinical levels of mental illness. It can also result in physical symptoms associated with anxiety and stress. For instance, one study found a relationship between perceived discrimination and higher levels of systolic blood pressure levels. ${ }^{16}$ In addition to negative health implications, perceived discrimination can affect self-control, increasing the likelihood of engaging in such unhealthy behaviors as smoking, drinking alcohol, suffering from sub-

\footnotetext{
${ }^{12}$ José-Miguel Rodríguez-García and Ulrich Wagner, "Learning to Be Prejudiced: A Test of Unidirectional and Bidirectional Models of Parent-Offspring Socialization," International Journal of Intercultural Relations 33, no. 6 (2009): 516-23. https://doi.org/10.1016/j.ijintrel.2009.08.001.

${ }^{13}$ Thomas Pettigrew, Ulrich Wagner, and Oliver Christ, "Relative Deprivation and Intergroup Prejudice," Journal of Social Issues (June 2008). https://doi.org/10.1111/j.1540-4560.2008. 00567.x.

${ }^{14}$ Thomas F. Pettigrew, "The Ultimate Attribution Error: Extending Allport's Cognitive Analysis of Prejudice," Personality and Social Psychology Bulletin 5, no. 4 (1979): 461-76. https://doi. org/10.1177/014616727900500407.

15 Gordon W. Allport, Kenneth Clark, and Thomas Pettigrew. The Nature of Prejudice (New York: Basic Books, 2015).

${ }^{16}$ Elizabeth A. Pascoe and Laura Smart Richman, "Perceived Discrimination and Health: A MetaAnalytic Review," Psychological Bulletin 135, no. 4 (September 2009): 531-54. https:/doi.org/ 10.1037/a0016059.
} 
stance abuse, practicing unsafe sex, and neglecting cancer screening and diabetes management. ${ }^{17}$

Importantly, prejudice may exist toward a particular group, and yet discrimination will not follow. Despite holding such negative attitudes, an individual may still treat members of this group respectfully and equally. One must understand that, especially for institutions and organizations, unintentional discrimination may result from discriminatory practices and policies. ${ }^{18}$

Stereotypes, prejudice, and discrimination all play a role in the larger issue of xenophobia, commonly defined as a form of prejudice that entails fear and hatred of strangers, immigrants, and foreigners. Xenophobia is based on the belief that being native to a certain country is more important to national identity than sharing the nation's ideals and values. Recent definitions emphasize the role of ethnocentrism, the belief that one's ethnic or racial group is superior to others; nationalism, the belief that one's nation is superior; and "high social dominance orientation," the belief that inherent social hierarchies exist. ${ }^{19}$

There are several theories about the factors that lead to and aggravate xenophobia. The realistic conflict theory suggests that feelings of xenophobia increase when in-group members begin to view out-group members as competitors for limited resources. The integrated theory of prejudice goes beyond economic threat, suggesting that four types of threats lead to prejudice and ultimately xenophobia: realistic threat (competition), symbolic threat (differences in values and beliefs), intergroup anxiety (difficult interactions with a person from an unfamiliar culture), and negative stereotypes. ${ }^{20}$ Many other theories expand on these definitions; however, in summary, the key point is that xenophobia is rooted in real fears.

Similar to xenophobia, racism, another form of oppression, is the socially constructed belief that certain groups of people who share similar physical, cultural, ancestral, linguistic, religious, or social characteristics are inferior or superior to others. This idea is used to justify the unequal and unfair treatment of different groups of people. The common denominator in racism and xenophobia is the conscious distinction and tension between us (the "in group") and them (the "out group"). With the "we feeling" and subsequent solidarity in one's group as the standard, that group can judge other groups by their own groups' standards and values, thereby producing a view that one's own group is superior to others.

\footnotetext{
${ }^{17}$ Ibid.

${ }^{18}$ Benjamin P. Bowser, "Racism: Origin and Theory," Journal of Black Studies 48, no. 6 (July 2017): 572-90. https://doi.org/10.1177/0021934717702135.

${ }^{19}$ Oksana Yakushko, "Xenophobia." The Counseling Psychologist 37, no. 1 (December 2008): 36-66. https://doi.org/10.1177/0011000008316034.

${ }^{20}$ Ibid.
} 
Despite these commonalities, racism and xenophobia are also distinct. Racism is generally associated with visible markers of difference, such as skin color, whereas xenophobia targets foreigners, regardless of race. Islamophobia is considered a form of xenophobia. Furthermore, racism is rooted in presumed race superiority, whereas xenophobia is rooted in the presumed superiority of one's country or nation. They further differ because they are caused by different social hardships. Racism, especially in the US, was historically influenced by sociocultural factors, including slavery, segregation, and colonization. Xenophobia, on the other hand, typically increases during times of economic and political instability or a significant influx of migrants and refugees. Nonetheless, both racism and xenophobia are responsible for the extreme violence and blatant human rights violations seen in many parts of the world. ${ }^{21}$

\section{Creating Cross-cultural Competency}

The previous sections have stressed the need for cross-cultural competency in clinical settings, given the recent rise in hate crimes toward minority religious, racial, and ethnic groups nationwide, especially toward American Muslims. This section will provide an in-depth review of definitions, theoretical frameworks, and examples of topics related to culture, implicit bias, and cultural competency. This will be followed by useful tools to increase cultural competency and decrease implicit bias in clinical settings.

Culture is generally defined as "the set of shared attitudes, values, goals, and practices that characterize an institution or organization." ${ }^{22}$ Many frameworks have been used to explain culture. The best known is Edward Hall's iceberg mod$\mathrm{el},{ }^{23}$ which separates culture into external (top of the iceberg) and internal (bottom of the iceberg) aspects and explains how people tend to internalize each of them. The first one encompasses a culture's superficial components, including clothes, food, music, language, and art, whereas the second one depicts those parts of the culture that impact unconscious thoughts and behaviors. For instance, gender roles, religious beliefs, political beliefs, and attitudes toward one's family are included in this category. We consciously choose to have certain attitudes toward a culture's external aspects, whereas our attitudes toward a culture's internal aspects are often involuntary thoughts and associations.

\footnotetext{
${ }^{21}$ Martin N. Marger, Race and Ethnic Relations: American and Global Perspectives (Boston: Cengage Learning, 2019).

22 "Culture." In Merriam-Webster Online Dictionary. Merriam-Webster, 2020.

${ }^{23}$ Edward Twitchell Hall, Beyond Culture (New York: Doubleday/Anchorbooks, 1976).
} 
Implicit bias causes unintentional actions on unconsciously held prejudices. ${ }^{24} \mathrm{~A}$ useful tool for measuring these associations is the online Implicit Association Tests (IAT) tests, which measure how quickly a person makes associations between different stereotypes. In other words, these tests measure a person's implicit bias. The IAT tests peoples' attitudes on a multitude of issues, including race, disability, religion, sexuality, and skin color. ${ }^{25}$ People may believe they are not racist and therefore treat white and black people equally, but IATs may show otherwise. For example, IAT results show that white individuals tend to perceive the same expressions on black faces as angrier than on white faces. ${ }^{26}$ A 2012 study demonstrated the role implicit bias plays in how pediatricians treat patients in a healthcare setting. The results showed that pediatricians with pro-white implicit biases were less likely to prescribe painkillers to black patients than to white patients. ${ }^{27}$

The question of whether or not implicit bias tests predict the likelihood of discriminatory behavior has been widely discussed and debated. Researchers of implicit bias discourage the use of IAT tests to determine individual behavior, suggesting that it should be used to predict average group behavior instead. The IAT is better at predicting outcomes across counties and cities and showing a correlation between low implicit bias and lower racial disparities in police shootings, for example. ${ }^{28}$ Thus, although IAT provides some insight into individuals' implicit bias and prejudice, it should not be used to take actions against an individual; rather, it should be used to tackle an organization's culture.

With the development of implicit bias tests, various efforts across organizations and companies have emerged to proactively combat implicit bias. ${ }^{29}$ The medical sector has been at the forefront of these implicit bias trainings, sparked by the Hippocratic oath taken by all physicians to "first do no harm." This oath ultimately translates into the core medical ethos of appropriate bedside manners with all patients, no matter how different they may be from the physician treating them. One such example is the "Bias and Sociocultural Awareness in Clinical Set-

\footnotetext{
${ }^{24}$ Michael Brownstein, “Implicit Bias,” Stanford Encyclopedia of Philosophy (Stanford University, July 31, 2019). https://plato.stanford.edu/entries/implicit-bias/.

${ }^{25}$ Malcolm Gladwell, Blink: The Power of Thinking without Thinking (New York: Little, Brown and Co., 2005).

26 "Understanding Implicit Bias," Kirwan Institute for the Study of Race and Ethnicity (The Ohio State University, 2015). http://kirwaninstitute.osu.edu/research/understanding-implicit-bias/.

${ }^{27}$ Elizabeth N. Chapman, Anna Kaatz, and Molly Carnes, "Physicians and Implicit Bias: How Doctors May Unwittingly Perpetuate Health Care Disparities," Journal of General Internal Medicine 28, no. 11 (November 2013): 1504-10. https://doi.org/10.1007/s11606-013-2441-1.

${ }^{28}$ Keith Payne, "How to Think about 'Implicit Bias,"” Scientific American (March 27, 2018). https://www.scientificamerican.com/article/how-to-think-about-implicit-bias/.

${ }^{29}$ Shamika Dalton and Michele Villagran, "Minimizing and Addressing Implicit Bias in the Workplace: Be Proactive, Part One," College \& Research Libraries News 79, no. 9 (April 2018): 478. https://doi.org/10.5860/crln.79.9.478.
} 
tings" manual developed by the Stanford University School of Medicine for their medical students and residents. This manual includes several online scenarios to expose them to different cross-cultural situations that help inform them of their potential conscious and unconscious biases. After reviewing them, the students convene in small discussion groups to discuss how to overcome these potential barriers in cross-cultural interactions. ${ }^{30}$

The goals of Stanford Medicine's training manual used in the course, as well as other similar manuals, is to improve an individual's ability to work respectfully with people across different cultures and, as such, raise their cultural competency. ${ }^{31}$ On a micro-level, this ultimately means training individuals to think, feel, and behave in ways that respect diversity. On a large-scale level, this means incorporating knowledge about cultural norms into policies and practices. ${ }^{32}$

In order to reach full cross-cultural competency and reduce one's implicit biases, one must understand the step-by-step process involved in achieving mastery. The first step to combating implicit bias is to evaluate one's "status" in cultural competency. In order to accomplish this task, in 1989 Terry Cross developed the Cultural Competency Continuum framework. ${ }^{33}$ This continuum describes cultural competency's different stages, which range from the lowest level of cross-cultural interactions, "cultural destructiveness," to the highest level, "cultural proficiency." Its different stages, along with their definitions and related attitudes, are described below:

1. Cultural Destructiveness: This group has the lowest level of cross-cultural interactions. Individuals at this stage hold biases toward certain cultures, viewing them as inferior to their own. This attitude is often accompanied by intentional desires and efforts to suppress minority voices and rights.

2. Cultural Incapacity: While this group lacks the skills and knowledge to deal with diverse populations, they do not have an active desire to suppress individuals from minority groups.

3. Cultural Blindness: This group assumes that the same interaction is appropriate toward majority and minority people. Furthermore, they have not acknowledged their own biases.

\footnotetext{
${ }^{30}$ Fernando Mendoza and Lars Osterberg, Bias and Sociocultural Awareness in Clinical Settings (Cedar Interactive, 2018).

${ }^{31}$ J. H. Hanley, "Beyond the Tip of the Iceberg," Reaching Today's Youth: The Community Circle of Caring Journal 3, no. 2 (1999): 9-12.

${ }^{32}$ King Davis, "Exploring the Intersection Between Cultural Competency and Managed Behavioral Health Care: Implications for State and County Mental Health Agencies." NASMHPD Publications (December 1997).

${ }^{33}$ Terry L. Cross, Marva P. Benjamin, and Mareasa R. Isaacs, Towards a Culturally Competent System of Care (Washington, D.C.: CASSP Technical Assistance Center, Georgetown University Child Development Center, 1989).
} 
4. Cultural Pre-Competence: This group of individuals have recognized their biases, acknowledged them as problematic, and have taken action to correct them. However, they are satisfied with minimal progress. In other words, individuals at this stage are more concerned about being absolved of cultural incompetence than about taking committed steps to create a welcoming environment for people of different backgrounds.

5. Cultural Competence: At this stage, individuals have made a commitment to improving the experiences of diverse populations and taken steps toward sustained structural and systematic improvement.

6. Cultural Proficiency: At this stage, respect for diversity is part of an organization's central goal. This is demonstrated by its leadership's ideals and active role in advocating for better cross-cultural interactions. ${ }^{34}$

To progress along the cultural competency continuum, an individual/organization must constantly reevaluate its status, seek feedback, adapt, and invest in new training. ${ }^{35}$

Efforts to improve cultural competency can be further supplemented with Pedersen's Developmental Model, a four-step process that provides a framework for targeting one's attitudes and implicit biases toward different cultural groups. The first step, awareness, is acknowledging the biases that one holds. ${ }^{36}$ This requires introspection and cognizance of one's own thought processes and attitudes. ${ }^{37}$ The second step, knowledge, is attaining factual information about the diversity across and within cultures. The third step, skills, is integrating this knowledge into practice. The fourth and final step, attitude, is adopting the mindset that diversity and change are both crucial and positive. ${ }^{38}$

Other tools, specifically in the mental health field, exist to help professionals achieve cultural proficiency. An example is the DSM-5 Outline for Cultural Formulation, an interview guideline that helps clinicians gather culturally relevant information from patients. ${ }^{39}$ The interview model includes gathering information about their cultural identity and understanding distress, mental illness, the psychosocial environment, functioning factors, and attitudes toward a patient-physician relationship in their cultural context. Other tools and trainings have been devel-

\footnotetext{
${ }^{34}$ Hanley, "Beyond the Tip of the Iceberg."

${ }^{35}$ Davis, "Cultural Competence."

${ }^{36}$ Cunningham, Leigh, "Multicultural Awareness Issues for Academic Advisors," Academic Advising Today (November 2012).

${ }^{37}$ Kimberly Tanner and Deborah Allen, "Cultural Competence in the College Biology Classroom," CBE-Life Sciences Education 6, no. 4 (2007): 251-58. https://doi.org/10.1187/cbe.07-090086.

${ }^{38}$ Cunningham, "Multicultural Awareness Issues."

39 "Cultural Formulation," MMHRC (Multicultural Mental Health Resource Center, April 2, 2019). http://www.multiculturalmentalhealth.ca/en/clinical-tools/cultural-formulation/.
} 
oped that particularly focus on Muslim populations. This includes chapters in the book Islamophobia and Psychiatry such as "Psychiatric Cultural Formulation in the Islamophobic Context," "Clinical Assessment," "Tools for the Culturally Competent Treatment of Muslim Patients," and "Community Resilience."40

As with implicit bias, similar tests have been developed to asses cultural competency skills. The Cultural Quotient (CQ) measures cultural intelligence, defined as a person's ability to respond appropriately in various cultural contexts. This includes measuring his/her understanding of different cultures, ability to problem solve and adapt to various broadly defined cultural settings, understanding of how cultural contexts affect cognition, and the similarities and differences among cultures. ${ }^{41}$ As the world becomes increasingly globalized, interactions with people from different backgrounds, ethnicities, religions, and languages have become commonplace. As a result, cultural intelligence is a critical skill to have today. This calls for the development of more and improved education modules to help individuals, specifically clinicians, progress through the cultural competency continuum and constantly strive toward cultural proficiency.

\section{Conclusion}

Returning to the clinical vignette that introduced this paper, the patient Renda clearly has experiences that are deeply influenced by her religious and cultural background. Living as a religious minority in the US, Renda is well aware that many Americans perceive her negatively. Her family has been directly impacted by hate- her son has experienced religious-based bullying at his school. This further increases her stress as she strives to "represent Islam in a good light" and change the perceptions she believes many Americans have of Muslims.

All of these discrimination-based stressors, interrelated with prejudice, bias, racism, and xenophobia, significantly impact both her mental and physical health. As this paper has discussed, a key means to respond to this hate is by supporting victims within the clinical setting. This means an extra emphasis on clinicians acquiring the skills needed to enable culturally sensitive care and support for patients like Renda, who experience Islamophobic discrimination.

\section{Bibliography}

Davies, Anna, Devin Fidler, and Marina Gorbis. "Future Work Skills 2020," n.d. Ali, Sara, and Rania Awaad. "Islamophobia and Public Mental Health: Lessons Learned from Community Engagement Projects." Islamophobia and Psychiatry, 2018, 375-90. https://doi.org/10.1007/978-3-030-00512-2_31.

\footnotetext{
${ }^{40}$ Moffic, Peteet, Hankir, and Awaad, Islamophobia and Psychiatry.

${ }^{41}$ Elaine Mosakowski and P. Christopher Earley, "Cultural Intelligence," Harvard Business Review (October 2004).
} 
Allport, Gordon W., Kenneth Clark, and Thomas Pettigrew. The Nature of Prejudice. New York: Basic Books, 2015.

Bowser, Benjamin P. "Racism: Origin and Theory." Journal of Black Studies 48, no. 6 (July 2017): 572-90. https://doi.org/10.1177/0021934717702135.

Brownstein, Michael. "Implicit Bias." Stanford Encyclopedia of Philosophy. Stanford University, July 31, 2019. https://plato.stanford.edu/entries/implicitbias/.

Chapman, Elizabeth N., Anna Kaatz, and Molly Carnes. "Physicians and Implicit Bias: How Doctors May Unwittingly Perpetuate Health Care Disparities." Journal of General Internal Medicine 28, no. 11 (November 2013): 150410. https://doi.org/10.1007/s11606-013-2441-1.

"Council on American-Islamic Relations." CAIR. Council on American Islamic Relations, 2020. https://www.cair.com/.

Cross, Terry L., Marva P. Benjamin, and Mareasa R. Isaacs. Towards a Culturally Competent System of Care. Washington, D.C.: CASSP Technical Assistance Center, Georgetown University Child Development Center, 1989.

"Cultural Formulation." MMHRC. Multicultural Mental Health Resource Center, April 2, 2019. http://www.multiculturalmentalhealth.ca/en/clinical-tools/ cultural-formulation/.

Cunningham, Leigh. "Multicultural Awareness Issues for Academic Advisors." Academic Advising Today, November 2012.

Dalton, Shamika, and Michele Villagran. "Minimizing and Addressing Implicit Bias in the Workplace: Be Proactive, Part One." College \& Research Libraries News 79, no. 9 (April 2018): 478. https://doi.org/10.5860/crln. 79.9.478.

Davis, King. "Exploring the Intersection Between Cultural Competency and Managed Behavioral Health Care: Implications for State and County Mental Health Agencies." NASMHPD Publications, December 1997.

Gladwell, Malcolm. Blink: The Power of Thinking without Thinking. New York: Little, Brown and Co., 2005.

Hall, Edward Twitchell. Beyond Culture. New York: Doubleday, 1989.

Judd, Charles M., and Bernadette Park. "Definition and Assessment of Accuracy in Social Stereotypes." Psychological Review 100, no. 1 (1993): 109-28. https://doi.org/10.1037/0033-295x.100.1.109.

Khan, Saera R. "Post 9/11: The Impact of Stigma for Muslim Americans." Peace and Conflict: Journal of Peace Psychology 20, no. 4 (2014): 580-82. https://doi.org/10.1037/pac0000063.

Marger, Martin N. Race and Ethnic Relations: American and Global Perspectives. Boston: Cengage Learning, 2019. 
McGarty, Craig, Russell Spears, and Vincent Y. Yzerbyt. Stereotypes as Explanations: The Formation of Meaningful Beliefs about Social Groups. Cambridge: Cambridge Univ. Press, 2002.

Mendoza, Fernando, and Lars Osterberg. Bias and Sociocultural Awareness in Clinical Settings. Cedar Interactive, 2018.

“Culture." In Merriam-Webster Online Dictionary. Merriam-Webster, 2020.

Moffic, H. Steven, John R. Peteet, Ahmed Zakaria Hankir, and Rania Awaad. Islamophobia and Psychiatry: Recognition, Prevention, and Treatment. Cham, Switzerland: Springer, 2019.

Mosakowski, Elaine, and P. Christopher Earley. "Cultural Intelligence." Harvard Business Review, October 2004.

O'Brien, John. "Spoiled Group Identities and Backstage Work." Social Psychology Quarterly 74, no. 3 (April 2011): 291-309. https://doi.org/10.1177/ 0190272511415389.

Pager, Devah, and Hana Shepherd. "The Sociology of Discrimination: Racial Discrimination in Employment, Housing, Credit, and Consumer Markets." Annual Review of Sociology 34, no. 1 (2008): 181-209. https://doi.org/ 10.1146/annurev.soc.33.040406.131740.

Pascoe, Elizabeth A., and Laura Smart Richman. "Perceived Discrimination and Health: A Meta-Analytic Review." Psychological Bulletin 135, no. 4 (September 2009): 531-54. https://doi.org/10.1037/a0016059.

Payne, Keith. "How to Think about 'Implicit Bias."' Scientific American, March 27, 2018. https://www.scientificamerican.com/article/how-to-think-aboutimplicit-bias/.

Pettigrew, Thomas F. "The Ultimate Attribution Error: Extending Allport's Cognitive Analysis of Prejudice." Personality and Social Psychology Bulletin 5, no. 4 (1979): 461-76. https://doi.org/10.1177/014616727900500407.

Pettigrew, Thomas, Ulrich Wagner, and Oliver Christ. "Relative Deprivation and Intergroup Prejudice." Journal of Social Issues, June 2008. https://doi. org/10.1111/j.1540-4560.2008.00567.x.

Plous, Scott. Understanding Prejudice and Discrimination. Boston: McGraw Hill, 2003.

"Preventing and Responding to Hate Crimes: A Resource Guide for NGOs in the OSCE Region.” Warsaw, Poland: Organization for Security and Cooperation in Europe, 2009.

Rodríguez-García, José-Miguel, and Ulrich Wagner. "Learning to Be Prejudiced: A Test of Unidirectional and Bidirectional Models of Parent-Offspring Socialization." International Journal of Intercultural Relations 33, no. 6 (2009): 516-23. https://doi.org/10.1016/j.ijintrel.2009.08.001. 
Rosentiel, Tom. "Muslim Americans: Middle Class and Mostly Mainstream." Pew Research Center, December 30, 2019. https://www.pewresearch.org/ 2007/05/22/muslim-americans-middle-class-and-mostly-mainstream/.

Samari, Goleen, Héctor E. Alcalá, and Mienah Zulfacar Sharif. "Islamophobia, Health, and Public Health: A Systematic Literature Review." American Journal of Public Health 108, no. 6 (2018). https://doi.org/10.2105/ ajph.2018.304402.

Sibley, Chris G, and Danny Osborne. "Prejudice." The SAGE Encyclopedia of Political Behavior, 2017. https://doi.org/10.4135/9781483391144.n292.

Tanner, Kimberly, and Deborah Allen. "Cultural Competence in the College Biology Classroom." CBE—Life Sciences Education 6, no. 4 (2007): 25158. https://doi.org/10.1187/cbe.07-09-0086.

"Understanding Implicit Bias." Kirwan Institute for the Study of Race and Ethnicity. The Ohio State University, 2015. http://kirwaninstitute.osu.edu/ research/understanding-implicit-bias/.

Wayne, Weiten. Psychology: Themes and Variations. Boston: Cengage Learning, 2010.

Yakushko, Oksana. "Xenophobia." The Counseling Psychologist 37, no. 1 (December 2008): 36-66. https://doi.org/10.1177/0011000008316034. 